\title{
EDITORIAL
}

\section{Development of the Journal}

In my last Editorial I wrote of the need for a scientific journal to develop alongside the scientific field that it was serving, and that this meant one had to be especially receptive to the papers that were at the interface between nutrition and the other disciplines which could contribute to the development of nutritional concepts and the resolution of nutritional hypotheses that were not sensitive to the existing techniques at our disposal. For example, when I was a member of the Editorial Board under George Pitt there was a tradition that the British Journal of Nutrition was suspicious of 'modelling' papers. Primarily I think that this stemmed from a view that the Journal was concerned with publishing the conventional experimental research paper where either animals or human subjects were fed in a controlled way and one observed the responses, or where observational studies had been undertaken to study the effects of 'natural experimental' variations in dietary intakes. Modelling papers were seen as rather theoretical and, to be fair to the Editor, many at that time involved mathematical manipulations of data to fit observed phenomena without a firm biological basis for the manipulations. Modelling, however, has now become a central technique in nutritional studies, primarily because biological hypotheses now form the bases from which the mathematical models are developed. Modelling of the complex biochemical fluxes in metabolism has become a very powerful tool for testing alternative hypotheses and, in effect, enables the researcher to restrict the experimental studies to those which the model has shown are central to the evaluation of the hypothesis. In many respects modelling provides one means of maximizing the efficiency of research and the use of physical and animal resources.

There are some other aspects of the development of the British Journal of Nutrition and the other publications of the Nutrition Society that I would like to describe in this Editorial to illustrate how we think the Journal should develop.

First, we believe that the publications of the Society need to be considered together: it is clear that the Proceedings of the Nutrition Society and Nutrition Research Reviews have their own special features and places in the scientific literature; nevertheless we have decided that some areas, such as technical editing, could with advantage be more closely integrated, and so we have formed an Editorial Policy Group. This group will deal with the technical publishing aspects but will also be forward-looking and seek to identify where the publications should be going; for example, we clearly will need to expand our use of computerization and move to receiving the editing papers on disk. Developments in this area, just over the horizon, have important implications for all scientific journals and we think that we should be prepared. This Policy Group will liaise very closely with the publisher on the financial aspects of our publications. I think that it is particularly important that scientific decisions, accompanied by financial prudence, should govern the way forward. In this respect we are fortunate as a Society to own our journals. This means that we have to ensure that the Journal maintairs its scientific standards and attracts the best range of nutritional research publications. In a real sense a scientific journal is in a special position because its subscribers and readers are for the most part its contributing authors or aspiring contributors, so that our clear role is to provide a Journal where authors wish to publish. This means that we must search continually to provide sound and fair peer review and to process papers as quickly as the maintenance of this review permits. 
In the past year it has become clear that some members of the Editorial Board were being overworked and also that some growth areas were not covered adequately by the present members of the Board. In the last few months Ian Sambrook and the staff in the Office and I have been looking at the 'paper loading' of the different members and trying to identify where an editor was being overloaded with its consequential effects on the speed and willingness of the editor to deal with papers. The members of the Editorial Board are all active researchers and are increasingly subject to the growing pressures placed on all scientific researchers at the present time, the increasing administrative load and the continuous quest for research funding and, for many, the growing numbers of reports which need to be written during the course of a project. In the past writing-up was often limited to the scientific papers describing the research; now, I suspect, the greater volume of written scientific work lies in proposals for funding and progress reports, and heaven help the scientist who finds writing a chore. As a result of this analysis we propose some expansion of the Board to deal with popular areas, although all members of the Board have occasionally to deal with papers outside their field with the assistance of referees.

While mentioning the Editorial Board I must mention one Editor whose term has come to an end: Mike Gurr, my immediate predecessor as Chairman of the Board. Mike played an important role in initiating a number of changes which modernized the appearance of the Nutrition Society's publications and also brought a keen rigorous scientific approach to editing papers. He played a critically important role during my first few months as Chairman, initiating me into the mysteries of the reviewing and publication process, and I give him my special thanks and those of his colleagues on the Board. The Editors of the Society's three publications are all acutely aware, by experience, of the difficulties facing a new editor, and we are looking into procedures that will provide some form of overlap so that a new editor is let in gradually to the duties required of him or her.

Finally, and most importantly, after very careful consideration we have decided that the British Journal of Nutrition will be published monthly from the beginning of 1994. There are several reasons for this change. The most important are those that are concerned with the organization of the publishing process. A monthly publication schedule will give us more flexibility in making-up the numbers of the Journal, and on a crude statistical basis at least half the papers will be published a month earlier than under the present schedules. We hope that monthly publication will improve the general flow of papers through the system and it will mean that we will not be delayed by a slow return of proofs.

Other benefits will be that 'Letters to the Editor' will be published sooner after a paper which provokes comment has appeared; also, we will be better placed to take notices of forthcoming meetings and other suitable advertising with the monthly schedule. We believe that it is more appropriate for a research journal such as the British Journal of Nutrition to be published more frequently in order to improve the communication of research.

D. A. T. Southgate 